\title{
Implications of Somatostatin Analogues in the Treatment of Acromegaly
}

\author{
Karim Gariani, ${ }^{1}$ Patrick Meyer ${ }^{2}$ and Jacques Philippe ${ }^{3}$ \\ 1. Chief Resident, Internal Medicine Service; 2. Associate Clinician; 3. Professor, Head, Division of Diabetology, \\ Endocrinology and Hypertension and Nutrition, Geneva University Hospital, Switzerland
}

\begin{abstract}
Octreotide has an important role in the medical management of acromegaly. Its place in the management of acromegaly as an adjuvant therapy after neurosurgery is well established with a well-demonstrated efficacy. It can also be used in certain clinical conditions as a neoadjuvant treatment. Clinicians and patients should be aware of the possible side effects of octreotide treatment.
\end{abstract}

\section{Keywords}

Acromegaly, somatostatin analogues, octreotide, treatment, side effects

Disclosure: The authors have no conflicts of interest to declare.

Received: 15 April 2013 Accepted: 13 May 2013 Citation: European Endocrinology, 2013;9(2):132-5 DOI:10.17925/EE.2013.09.02.132

Correspondence: Karim Gariani, Department of Internal Medicine, Division of General Internal Medicine, 4 rue Gabrielle-Perret-Gentil, 1211 Genève 4, Geneva, Switzerland

E: Karim.Gariani@hcuge.ch

\section{Acromegaly Epidemiology and Clinical Manifestations}

Acromegaly is an uncommon disorder characterised by the hypersecretion of growth hormone $(\mathrm{GH})$ resulting in an increase in serum insulin-like growth factor-1 (IGF-1) levels. This condition is most often caused by a pituitary adenoma. The prevalence is estimated around 40-125 per million and the incidence is around three to four new cases per million. ${ }^{1}$ Two studies have suggested that the prevalence of acromegaly may be more widespread than previously estimated. In a study including 71,972 subjects, the prevalence of pituitary adenoma was more than 3.5-5 times than previously reported, whereas in an another study the prevalence of biochemical acromegaly by screening for elevated IGF-1 levels was even higher with 1,043 cases per million of subjects. ${ }^{2,3}$ The mean age at diagnosis is around 40 years. The clinical manifestations of acromegaly are varied and comprise enlargement of the extremities, soft tissue swelling, coarsening of facial features, prognathism, macroglossia, increase in ring and/or shoe size, arthritis, hyperhidrosis and diabetes.

\section{Acromegaly Diagnosis Criteria}

The current international consensus for the diagnosis of acromegaly is based on the inability to suppress serum $\mathrm{GH}$ to less than $1 \mathrm{\mu g} / \mathrm{l}$ after glucose administration (75 $\mathrm{g}$ is recommended), in conjunction with a clinical suspicion and high IGF-1 levels. ${ }^{4}$

The diagnosis is often preceded by around 10 years of active unrecognised disease. ${ }^{5}$ The clinical manifestations of acromegaly depend on the level of GH and IGF-1, tumour size, the age of the patient and the delay in diagnosis.

\section{Treatment Options in Acromegaly}

The aims of therapy in acromegaly are alleviation of symptoms, complete tumour removal and a decrease in morbidity and mortality. ${ }^{6}$ complications linked to acromegaly are principally premature atherosclerosis, hypertrophic cardiomyopathy, diabetes, arthritis, sleep apnoea syndrome and polyps of the colon. ${ }^{7}$ The cause of death in acromegaly patients is cardiovascular disease in $60 \%$ of patients, $25 \%$ respiratory disease and $15 \%$ neoplasia. ${ }^{8}$

A biochemical complete control is achieved by a serum $\mathrm{GH}$ level $<1 \mu \mathrm{g} / \mathrm{l}$ with a sensitive immunoassay or $<2.5 \mu \mathrm{g} / \mathrm{I}$ with a sensitive enzyme-based immunoassay, normalisation of serum IGF-1 levels compared with age- and sex-matched controls and/or GH level under $0.4 \mu \mathrm{g} / \mathrm{l}$ after an oral glucose tolerance test (OGTT). ${ }^{4}$

Management of a patient with acromegaly requires a multidisciplinary collaboration with a general practitioner, endocrinologist, neurosurgeon and radiotherapist.

Primary surgical removal of the tumour is considered as the preferred treatment for acromegaly according to the guidelines of the American Association of Clinical Endocrinologists. ${ }^{4}$ Transsphenoidal surgery in particular is considered as the first approach in patients with microadenomas and in patients with macroadenomas that are associated with a mass effect. Surgical excision achieves a normalisation of serum IGF-1 in 56-68 \% patients with non-invasive macroadenomas and in 75-95 \% patients with microadenomas. ${ }^{9-11}$

Medical treatment is considered an adjuvant therapy in patients experiencing residual disease after surgical removal of the tumour. The only situations in which medical treatment with somatostatin analogues (SSAS) have been considered as a first-line therapy is in cases of macroadenomas with no local mass effect and a poor chance of surgical cure because of an extrasellar extension, for example in the cavernous sinus, in patients who refuse surgery and in patients with an important surgical risk. Radiotherapy is recommended for patients with acromegaly with unsuccessful surgical and/or medical therapy. The disadvantages of radiotherapy include the time delay between radiation administration and disease remission and the risk of hypopituitarism. Medical treatment is commonly admitted as an adjuvant therapy in cases of residual disease after surgery. ${ }^{5}$ 
The three classes of drugs available for treatment of acromegaly are SSAS, dopamine agonists and GH-receptor antagonists. SSAs were introduced in the 1980s, with octreotide being the first SSA to become available for clinical use.

Lanreotide was the second SSA introduced for clinical use and was developed in the 1990s. The first available pharmaceutical form of lanreotide was relatively short acting and required multiple daily dosing or subcutaneous infusion and this was soon superseded by the long-acting formulations of lanreotide..$^{12} \mathrm{~A}$ long-acting preparation of sustained release (SR) lanreotide extended the time interval of intramuscular injection to 7-14 days. ${ }^{13,14}$

There are several forms of octreotide available for medical therapies that are listed in Table 1.

Other medical treatments are available in acromegaly and include dopamine agonists, such as bromocripitine or cabergoline. The advantage of this class of treatment in comparison to octreotide is their oral administration and lower cost. However, their biochemical effects seem to be lower in comparison with octreotide. ${ }^{15-17}$ Pegvisomant is a $\mathrm{GH}$ receptor antagonist that is administered subcutaneously and has been used in the US since 2003 and in Europe since 2004. The longterm efficacy of this treatment is interesting as a monotherapy with reported normalisation of IGF-1 in 89 to 97 of cases. ${ }^{18,19}$

In the recent ACROSTUDY, which included 1,288 patients in real-life clinical practice, $88 \%$ of patients received once per day pegvisomant alone, while $36 \%$ were administered daily pegvisomant with another treatment. The results showed a biochemical control in $63 \%$ patients after 5 years. ${ }^{20}$ Two smaller studies showed a better biochemical response ranging from $84 \%$ to $88 \%$ in patients receiving a more optimal dose titration. ${ }^{21,22}$

Combination therapy including octreotide and one of the other of treatments seems to be a valuable therapeutic option in some cases. Several studies have evaluated the different combination options. Concerning the addition of dopamine agonists to SSAS a meta-analysis including 15 studies showed that adding dopamine in previously uncontrolled patients permit a normalisation of IGF-1 in $50 \%$ patients. ${ }^{23}$ Addition of pegvisomant in patients on octreotide therapy for those with uncontrolled acromegaly leads to a normalisation of IGF-1 in about $95 \%$ of patients. 23,24

\section{Mechanisms of Action of SSAS}

The use of long-acting release (LAR) octreotide for treatment of acromegaly is supported by more than 20 years of experience and clinical research. ${ }^{25}$ This synthetic somatostatin binds to somatotstatin-receptor subtypes 2, 3 and 5 and inhibits the release of 5-hydroxytryptamine (5-HT) and the secretion of IGF-1, insulin, glucagon, secretin, gastrin, pancreatic polypeptide (PP), vasoactive intestinal peptide (VIP) growth hormone and motilin. ${ }^{26}$ Octreotide acts through four mechanisms to decrease abnormal GH secretion in acromegaly. First, octreotide suppresses $\mathrm{GH}$ secretion from the pituitary gland and from $\mathrm{GH}$-secreting adenomas. Second, it decreases GH binding to hepatocytes. Third, it inhibits hepatic IFG-1 production and finally it controls tumour growth. ${ }^{27}$

\section{SSAs Form and Schema of Administration}

The available SSAS are octreotide and lanreotide. Octreotide is available for subcutaneous and intramuscular administration. The LAR of octreotide is delivered with an intramuscular injection in polymeric microspheres. ${ }^{28}$
Table 1: Forms of Somatostatin Analogues, Duration of Action and Dosage

\begin{tabular}{|c|c|c|c|}
\hline & $\begin{array}{l}\text { Mode of } \\
\text { Administration }\end{array}$ & $\begin{array}{l}\text { Duration of } \\
\text { Action }\end{array}$ & Dosage Target \\
\hline Octreotide & Subcutaneous & 6-8 hours & $150-300 \mu g / d a y$ \\
\hline Lanreotide SR & Intramuscular & 10-14 days & $\begin{array}{l}10-20 \mathrm{mg} / \\
2 \text { weeks }\end{array}$ \\
\hline Octreotide LAR & Intramuscular & 3-4 weeks & $\begin{array}{l}10-30 \mathrm{mg} / \\
4 \text { weeks }\end{array}$ \\
\hline $\begin{array}{l}\text { Lanreotide } \\
\text { Autogel }\end{array}$ & Subcutaneous & 4-6 weeks & $\begin{array}{l}60-120 \mathrm{mg} / \\
6 \text { weeks }\end{array}$ \\
\hline
\end{tabular}

The starting dose proposed for octreotide LAR is $20 \mathrm{mg}$ every 4 weeks that can be progressively increased to $30 \mathrm{mg}$ every week and rarely to $40 \mathrm{mg}$ every week when there is resistance. 29,30 Experts recommend a trial of octreotide 2 weeks before beginning LAR octreotide. For subcutaneous (SC) octreotide, the initial dose proposed is $50 \mu \mathrm{g}$ injected SC three to four times per day with a maximal dose of $1.5 \mathrm{mg}$ per day. Lanreotide is another long-acting SSA and is available in one form: lanreotide Autogel (ATG). Currently, lanreotide ATG is the only formulation available in the US. Lanreotide ATG is an aqueous solution that is administered subcutaneously and is available in 60,90 and $120 \mathrm{mg}$ mixtures.

Lanreotide ATG has a more favourable pharmacokinetic profile than SR lanreotide, which permits deep SC administration once every 28-56 days and by self-injection rather than muscular injection every 7-14 days. ${ }^{31}$ Elimination of octreotide is principally via biliary excretion. However the pharmacokinetic profile of octreotide is only slightly altered in patients presenting moderate to severe hepatic insufficiency, requiring no adjustment of its dosage. ${ }^{32}$ Clinicians should be cautious in patients already taking cyclosporin because of a potential decreased resorption of this drug by octreotide. ${ }^{33}$ Drugs that are metabolised by cytochrome P450 3A4, such as quinidine, have a reduction in their clearance in patients taking octreotide. Concerning octreotide itself, no drugs have been reported to alter its clearance.

\section{Efficacy of SSAS}

The efficacy of octreotide treatment as a primary treatment among different studies has shown that it achieves biochemical remission in a substantial number of patients. ${ }^{34-36}$ The rate of biochemical response varies from $34 \%$ to $60 \%$. The rate of significant tumour shrinkage (>20\%) was estimated in about $75 \%$ of patients included in a prospective study. ${ }^{34}$ An important retrospective study based on the German Acromegaly Register compared primary therapy with octreotide in 145 patients to surgical treatment in 554 patients. The rate of IGF-1 and GH normalisation was higher in the group of patients treated with surgery further supporting the role of tumour surgical resection as the mainstay in the treatment of acromegaly. ${ }^{37}$

Different studies have assessed octreotide as a neoadjuvant therapy before neurosurgery. Notably, tumour size reduction was observed in about $35 \%$ of patients in the preoperative period and the biochemical remission rate after surgery was between $24 \%$ to $42 \%$ for patients first treated with octreotide before surgery versus $10 \%$ to $23 \%$ for patients who only benefited from surgery. ${ }^{38-40}$

A randomised, placebo-controlled study including 108 patients with acromegaly receiving lanreotide ATG 60,90 or 120 mg every 28 days 
Table 2: Associated Side Effects with Somatostatin Analogues

\begin{tabular}{ll} 
Secondary effect with octreotide & Constipation \\
& Flatulence \\
Frequent (in about $10 \%$ of & Diarrhoea \\
patients taking octreotide) & Nausea \\
& Abdominal pain \\
& Gallstones \\
\hline Rare (in less than 1\% of patient & Glucose intolerance \\
taking SSA) & Hair loss \\
& Steatorrhoea \\
& Loss of appetite \\
& Itching \\
& Skin rash \\
& Thyroid problems \\
\end{tabular}

SSA = somatostatin analogue.

has shown that after four injections in half of the patients achieved biochemical remission. ${ }^{41} \mathrm{~A}$ systematic review has showed a total of $33 \%$ of patients experienced tumour shrinkage during lanreotide SR or ATG treatment in varying degrees from 10 to $77 \% .42$

A meta-analysis of 44 studies involving 1,852 patients compared the efficacy of lanreotide SR and octreotide LAR as postsurgical therapies. The results showed that the biochemical efficacy of LAR octreotide is greater than that of lanreotide SR among patients unselected for prior SSA responsiveness. However, there are some limitations in the results of this meta-analysis because the biochemical criteria for acromegaly remission were heterogeneous among the studies. ${ }^{43}$ When comparing the efficacy of LAR octreotide versus lanreotide ATG there was no significant difference in biochemical control or in tumour shrinkage. $.4,45$ Lanreotide has the advantage of a prolonged injection interval in $50 \%$ of patients. ${ }^{46}$

New somatostatin receptor ligands (SRLS) are being evaluated in clinical trials. A next-generation SRL - pasireotide (SOM230) - has a 40-fold greater affinity for somatostatin receptor 5 gene (SSTR5) than octreotide. A randomised, multicentre, open-label, crossover study including 60 patients has showed a biochemical response of $27 \%$ after 3 months of pasireotide. Another study with nine patients receiving pasireotide during 24 months showed a biochemical control of $33.3 \% .47,48$ This molecule may be more effective than lanreotide and octreotide for biochemical control and can be considered as in interesting future treatment with potential advantages over currently used SRLS. The chimeric molecule dopastatin was used in phase II trials and had poor results causing its development to be stopped.

\section{Side Effects of SSAS}

SSA therapy is generally well tolerated in most patients and treatment discontinuation related to adverse effects (AES) is mainly due to transient gastrointestinal symptoms ${ }^{49-51}$ (see Table 2). The most frequent side effects of SSAs are diarrhoea, abdominal discomfort, nausea and flatulence in relation to the inhibition of pancreatic exocrine secretions. In rare cases, development of malabsorption and steatorrhoea can occur and the introduction of pancreatic enzymes can resolve the problem. By inhibiting cholecystokinin secretion, ocretotide causes the formation of a more lithogenic and viscous bile leading to gallbladder sludge and gallstones in up to $30 \%$ to $60 \%$ of the patients, respectively. ${ }^{52}$ Ursodeoxycholic acid and chenodeoxycholic acid can be considered as a valid option to dissolve gallbladder sludge.
Erythema, injection-site discomfort and burning sensations are also frequently reported by patients under SSA treatment. These side effects can be avoided by warming the drug to room temperature before injection (storage of octreotide is required in a refrigerator). The formation of painful subcutaneous nodules following repeated administration of lanreotide ATG has been described. ${ }^{53}$

SSAS can also reduce gastrin secretion with a direct inhibitory effect on the secretion of intrinsic factor increasing the risk of chronic gastritis and pernicious anaemia. Surveillance should be carried out for pernicious anaemia and a B12 injection should be considered in such patients.

Concerning the potential effects on glucose homeostasis, octreotide influences remain difficult to predict. Indeed, octreotide may induce both inhibition of insulin secretion, but also improve insulin sensibility by inhibiting $\mathrm{GH}$ that itself cause insulin resistance.

A meta-analysis of 619 patients treated with octreotide showed no effects on glycated haemoglobin $\left(\mathrm{HbA}_{1 \mathrm{C}}\right)$ or fasting glucose levels, but showed a worsening response to OGTT. ${ }^{54}$ It could be considered that ocreotide can induce diabetes and patients treated with this therapy with previous diabetes may encounter reduced or increased insulin requirements and thus a regular control of blood glucose is recommended when SSA treatment is started. On the contrary, patients may also experience episodes of hypoglycaemia because of the inhibition of glucagon secretion. Hypothyroidism is another possible complication caused by octreotide because of the possible suppression of thyroid-stimulating hormone.

Others side effects that must be explained to patients are hair loss and bradycardia. Diffuse alopoecia remains a rare complication of octreotide therapy that occurs less frequently with the slow-release preparation and is fully reversible after discontinuation.

Clinicians should also be aware of possible kidney injury induced by octreotide as a case of acute kidney failure caused by octreotide therapy for acromegaly has been reported. ${ }^{55}$

Concerning pregnancy, data about octreotide use remain scarce as treatment was discontinued in most cases during pregnancy. There are, however, few studies showing that pregnancy is occasionally associated with a symptomatic increase of $\mathrm{GH}$ secretion during pregnancy. Medical treatment during pregnancy with dopamine agonists or SSAS appears to not cause significant complications or teratogenicity, but it may be associated with altered neonatal weight. Nevertheless, gestation may have a positive impact on acromegaly control both during and following pregnancy. ${ }^{56-58}$ In the absence of consistent data about octreotide, clinicians should weigh out the potential risks against the possible benefits of octreotide treatment during pregnancy.

Finally, no tachyphylaxia has been reported during long-term therapy for patients taking octreotide for acromegaly; however, a tachyphylaxia was observed in a patient taking octreotide for a neuroendocrine gastrointestinal tumour.

\section{Conclusion}

SSAs are considered a mainstay in acromegaly therapy. Its efficacy is clearly demonstrated by numerous studies. However, clinicians and patients should be aware of the possible AEs, which can often be easily controlled and rarely require the discontinuation of treatment. 
1. Holdaway IM, Rajasoorya, Epidemiology of acromegaly Pituitary, 1999;2(1):29-41.

2. Daly AF, Rixhon M, Adam C, et al., High prevalence of pituitary adenomas: a cross-sectional study in the province of Liege, Belgium, I Clin Endocrinol Metab, 2006;91:4769-75.

3. Schneider HJ, Sievers C, Saller B, et al., High prevalence of biochemical acromegaly in primary care patients with elevated IGF-1 levels, Clin endocrinol (OXf), 2008;69:432-5

4. Katznelson L, Atkinson JL, Cook DM, et al., American association of clinical endocrinologists medical guidelines for clinical practice for the diagnosis and treatement of

5. Elmed S, Acromegaly pathogenesis and treatment, $J$ Clin Invest, 2009:119(11):3189-202

6. Colao A, Ferone D, Marzullo P, et al., Systematic complications of acromegaly: epidemiology, pathogenesis, and Melmed S, Medical progress :acromegaly, $N$ Engl J Med 2006;355:2558-73.

8. Holdaway IM, Rajasoorya, Gamble GD, Factors influencing mortality in acromegaly, J Clin Endocrinol Metab, 2004;89:667-674.

9. Beauregard C, Truong U, Hardy J, et al., Long-term outcome and mortality after transsphenoidal adenectomy for acromegaly, Clin Endocrinol, 2003;58(1):86-91.

10. Nomikos P, Buchfelder M, Fahlbusch R, The outcome of surgery in 668 patients with acromegaly using current criteria of biochemical 'cure', Eur J Endocrinol, 2005;152(3):379-87.

11. De P, Rees DA, Davies N, et al., Transsphenoidal surgery for acromegaly in Wales: results based on stringent criteria of

12. Marek J, Lanreotide Autogel therapy in patients with acromegaly-current role and perspectives for the future, European Endocrinology, 2010;6:36-41.

13. Roelfsema F, Biermasz NR, Pereira AM, Romijn JA, Therapeutic options in the management of acromegaly: focus on lanreotide Autogel, Biologics, 2008:2:463-79.

14. Castinetti F, Saveanu A, Morange I, Brue T, Lanreotide for the treatment of acromegaly, Adv Ther, 2009;26:600-12.

15. Jaffe CA, Barkan AL, Treatment of acromegaly with dopamine agonists, Endocrinol Metab Clin North Am, 1992;21(3):713-35. Abs R, Verhelst J, Maiter D, et al., Cabergoline in the treatmen of acromegaly: a study in 64 patients, J Clin Endocrinol Metab, 1998;83(2):374-8,

17. Sandret L, Maison P, Chanson P, Place of cabergoline as primary and adjunctive treatment for acromegaly: a metaanalysis, I Clin Endocrinol Metab, 2011:96(5):1327-35.

18. Trainer PJ, Drake WM, Katznelson L, et al., Treatment of acromegaly with pegvisomant, a growth hormone-receptor antagonist pegvisomant, N Eng/ J Med, 2000;342(16):1171-7.

19. Van der Lely AJ, Hutson RK, Trainer PJ, et al., Long-term treatment of acromegaly with pegvisomant, a growth hormone receptor antagonist, Lancet, 2001;358(9295):1754-9.

20. Van der Lely A, Biller BM, Brue T, et al., Long-term safety of pegvisomant in patients with acromegaly: comprehensive review of 1288 subjects in ACROSTUDY, $J$ Clin Endocrino Metab, 2012;978(5)1589-97.

21. Higham $\mathrm{CE}$, Chung $\Pi$, Lawrance J, et al., Long-term experience of pegvisomant therapy as a treatment for acromegaly, Clin Endocrinol, 2009;71(1):86-91.

22. Marazuela M, Lucas T, Alvarez-Escola C, et al., Long-term treatment of acromegalic patients resistant to somatosta in analogues with the $\mathrm{GH}$ receptor antagonist pegvisomant: its efficacy in relation to gender and previous radiotherapy, Eur 」 Endocrinol, 2009; 160:535-42

23. Neggers SJ, De Herder WW, Janssen JA, et al., Combined treatment for acromegaly with long-acting somatostat analogues and pegvisomant: long-term safety for up to 4.5 years (median 2.2) of follow-up in 86 patients, Eur J Endocrinol, 2009;160(4):529-33.

24. Feenstra 1 , De Herder WW, Ten Have SM, et al. Combined therapy with somatostatin analogues and weekly pegvisomant in active acromegaly Lancet, 2005;365(9471):1644-6.

25. Anthony L, Freda PU, From somatostatin to ocreotide LAR : evolution of a somatostatin analogue, Curr Med Res Opin, 2009:25:2989-99.

26. McKeage K, Cheer S, Wagstaff AJ, Octreotide long-acting release (LAR): a review of its use in the management of acromegaly, Drugs, $2003: 63 \cdot 2473-99$.

27. Murray RD, Kim K, Ren SG, et al., Central and peripheral actions of somatostatin on the growht hormone-IGF-I axis, Clin Invest, 2004:114(3):349-56.

28. Grass P, Marbach P, Bruns C, et al., Sandostatin LAR (microencapsulated octreotide acetate) in acromegaly: pharmacokinetic and pharmacodynamic relationship Metabolism, 1996;45 (8 Suppl.):127-30

29. Fleseriu M, Clinical efficacy and safety results for dose escalation of somatostatin receptor ligands in patients with acromegaly: a literature review, Pituitary, 2011:14-14(2):18493.

30. Chanson P, Boerlin V, Aizenberg C, et al., Comparison of octreotide acetate LARA and lanreotide SR in patients with acromegaly, Clin Endocrinol (OXf), 2000;53:577-86.

31. Hu M, Tomlinson B, Pharmacokinetic evaluation of lanreotide, Expert Opin Drug Metab Toxicol, 2010;6(10):1301-12.

32. Tomlinson B, Thomas NG, Lan IW, et al., Pharmacokinetic profile of the somatostatin analogue lanreotide in individuals with chronic hepatic insuffisancy, Clin Pharmacokinet, 2006;45:1003-11.

33. Yee GC, McGuire TR, Pharmacokinetic drug interactions with cylcosporin, Clin Pharmacokinet, 1990:19:319-32.

34. Mercado $\mathrm{M}$, Borges $\mathrm{F}$, Bouterfa $\mathrm{H}$, et al. A prospective multicentre study to investigate the efficacy, safety and tolerability of octreotide LAR in the primary therapy of patients with acromegaly, Clin Endocrinol, 2007;66(6):859-68.

35. Colao A, Pivonello R, Rosato F, et al., First-line octreotideLAR therapy induces tumour shrinkage and controls hormone excess in patients with acromegaly: results from an open, prospective, multicentre trial, Clin Endocrinol, 2006;64(3):342-51.

36. Cozzi R, Montini M, Attanasio R, et al., Primary treatment of acromegaly with octreotide LAR: a long-term (up to nine years) prospective study of its efficacy in the control of disease activity and tumor shrinkage, I Clin Endocrinol Metab 2006;91(4):1397-403.

37. Petersenn S, Buchfelder M, Reincke M, et al., Results of surgical and somatostatin analog therapies and their combination in acromegaly: a retrospective analysis of the German Acromegaly Register, Eur J Endocrino 2008; 159(5):525-32.

38. Carlsen SM, Lund-Johansen M, Schreiner T, et al., Preoperative octreotide treatment in newly diagnosed acromegalic patients with macroadenomas increase cure short-term postoperative rates: a prospective, randomized trial, I Clin Endocrinol Metab , 2008;93(8):2984-90

39. Shen $\mathrm{M}$, Shou X, Wang Y, et al., Effect of presurgical longacting octreotide treatment in acromegaly patents with invasive pituitary macroadenomas: a prospective radomied study, Endocr J, 2010;57(12):1035-44.

40. Carlsen SM, Svartberg J, Schreiner T, et al., Six-month preoperative octreotide treatment in unselected, de novo patients with acromegaly: effect on biochemistry, tumor volume, and postoperative cure, Clin Endocrinol,
2011;74(6):736-43

41. Melmed S, Cook D, Schopohl J, et al., Rapid and sustained reduction of serum growth hormone and insulin-like growth factor-1 in patients with acromegaly receiving lanreotide Autogel therapy: a randomized, placebo-controlled, multicenter studywith a 52 week open extension, Pituitary, 2010;13:18-28.

42. Mattiotti G, Giustina A, Effects of lanreotide SR and Autogel on tumor mass in patients with acromegaly: a systematic review, Pituitary, 2010;13:60-67.

43. Freda PU, Katznelson L, Van der Lely AJ, et al., Long-acting somatostatin analog therapy of acromegaly: a meta-analysis, I Clin Endocrinol Metab, 2005:90:4465-73.

44. Tutuncu Y, Berker D, Isik S, et al., Comparison of octreotide LAR and lanreotide autogel as post-operative medical treatment in acromegaly, Pituitary, 2012:15(3):398-404.

45. Murray RD, Melmed S, A critical analysis of clinically available somatostatin analog formulations for therapy of acromegaly, J Clin Endocrinol Metab, 2008;93(8):2957-68.

46. Schopohl J, Strasburger CJ, Caird D, et al., Efficacy and acceptability of lanreotide autogel $120 \mathrm{mg}$ at different dose
intervals in patients with acromegaly previously treated with ocreotide LAR, EXP Clin Endocrinol Diabetes, 2011;119(3):156-62.

47. Petersenn S, Schopohl J, Barkan A, et al., Pasireotide (SOM230) demonstrates efficacy and safety in patients with acromegaly: a randomized, multicenter, phase II trial, J Clin Endocrinol Metab, 2010;95(6):2781-9.

48. Petersenn S, Farrall AJ, Block C, et al., Long-term efficacy and safety of subcutaneous pasireotide in acromegaly: results from an open-ended, multicenter, Phase II extension study, Pituitary, 2013; Epub ahead of print.

49. Melmed S, Casanueva F, Cavagnini F,et al., Consensus statment: medical managments of acromegaly, Eur 1 Endocrinol, 2005;153:737-40

50. Feelders RA, Hofland $\mathrm{L}$, van Aken MO, et al., Medical therapy of acromegaly: efficacy and safety of somatostatin analogues, Drugs, 2009;69(16):2207-26.

51. Edling KL, Heaney AP, An update on the treatment of acromegaly, Plockinger U, Dienemann D, Quabbe HJ, Gastrointestinal side-effects of octreotide during long term treatement of acromegaly, I Clin Endocrinol Metab, 1990;71(6):1658-62.

Andries M, Glintborg D, Kvitsborg A, et al., A 12-month randomized crossover study on the effects of lanreotide autogel and octreotide long-acting repeatable on $\mathrm{GH}$ and IGF-1 in patients with acromegaly, Clin Endocrinol, 2008;68(3):473-80.

54. Mazziotti G, Floriani I, Bonadonna S, et al., Effects of somatostatin analogs on glucose homeostasis: a metaanalysis of acrom

55. Gariani K, de Seigneux S, Courbebaisse M, et al., Oxalate nephropathy induced by octreotide treatment for acromegaly: a case report, I Med Case Rep, 2012;6(1):215.

56. Fassmacht M, Capeller B, Arlt W, et al., LAR treatment throughout pregancy in an acromegalic woman, Clin Endocrinol, 2006;155:411-15.

57. Cheng S, Grasso L, Martinez-Orozco JA, et al., Pregnancy in acromegaly: experience from two referral centers and systematic review of the literature, Clin Endocrinol (OXf), 2012; $76(2): 264-71$

58. Caron P, Broussaud S, Bertherat J, et al., Acromegaly and pregnancy: a retrospective multicenter study of 59 pregnancies in 46 women, $J$ Clin Endocrinol Metab, 2010;95(10):4680-87. 